PROYECTOS

\title{
Que lo que está colgado toque el suelo
}

What is suspended should touch the ground

\section{Marco Godoy}

Recibido: octubre 2016

Aprobado: enero 2017

\section{Biografía}

\section{Marco Godoy}

Godoy.eme@gmail.com

www.marcogodoy.com

Marco Godoy (Madrid, 1986) es licenciado en Bellas Artes por la Universidad Complutense de Madrid y ha ampliado su formación en el departamento de Film, Video \& New Media de la School of the Art Institute of Chicago. En 2012-2014 cursa un Máster en el Royal College of Art de Londres, donde vive desde entonces.

$\mathrm{Su}$ obra se ha mostrado en instituciones y galerías como Matadero Madrid o Centre d'art la Panera de Lleida en España, Palais de Tokio y Centre Georges Pompidou en París (Francia), ICA y Whitechapel Gallery en Londres, Liverpool Biennial (Reino Unido), Herzliya Museum of Contemporary Art de Tel Aviv y Dallas Museum of Contemporary Art (EE.UU.), entre otros.

\section{Cita Recomendada}

Godoy, M. (2017). Que lo que está colgado toque el suelo. Sin Objeto, 00, 127-137 Doi: http://dx.doi.org/10.18239/sinobj_2017.00.09 

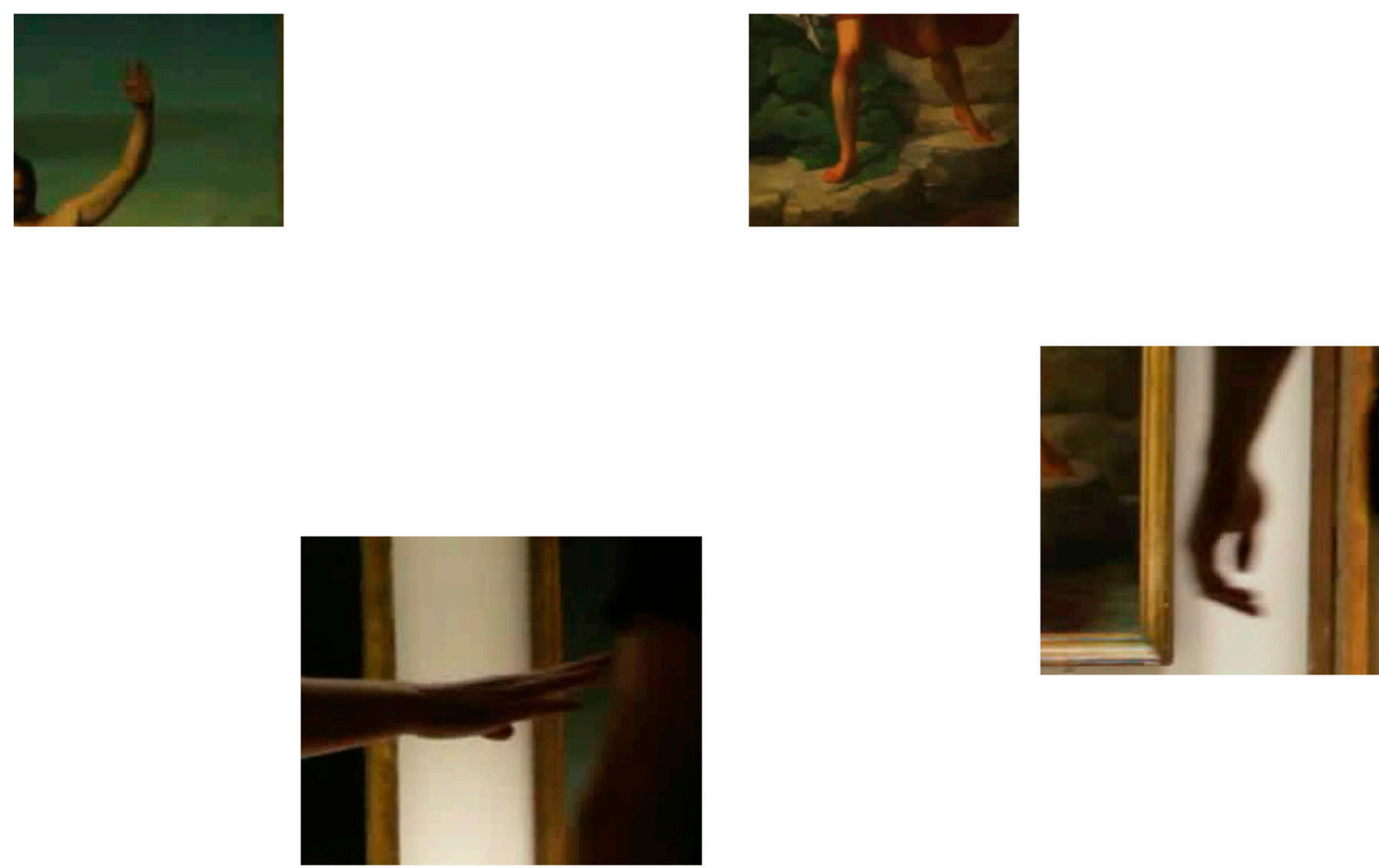

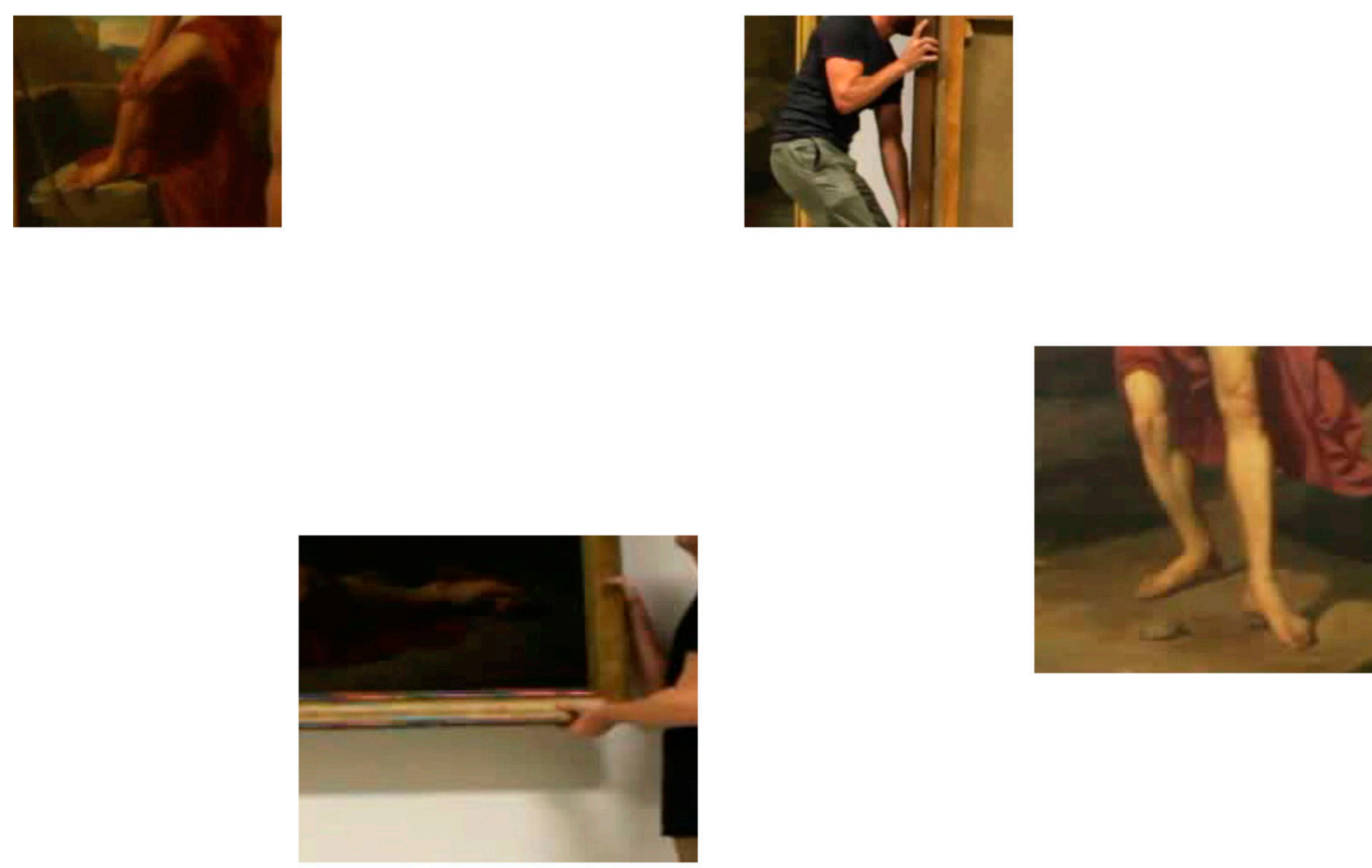

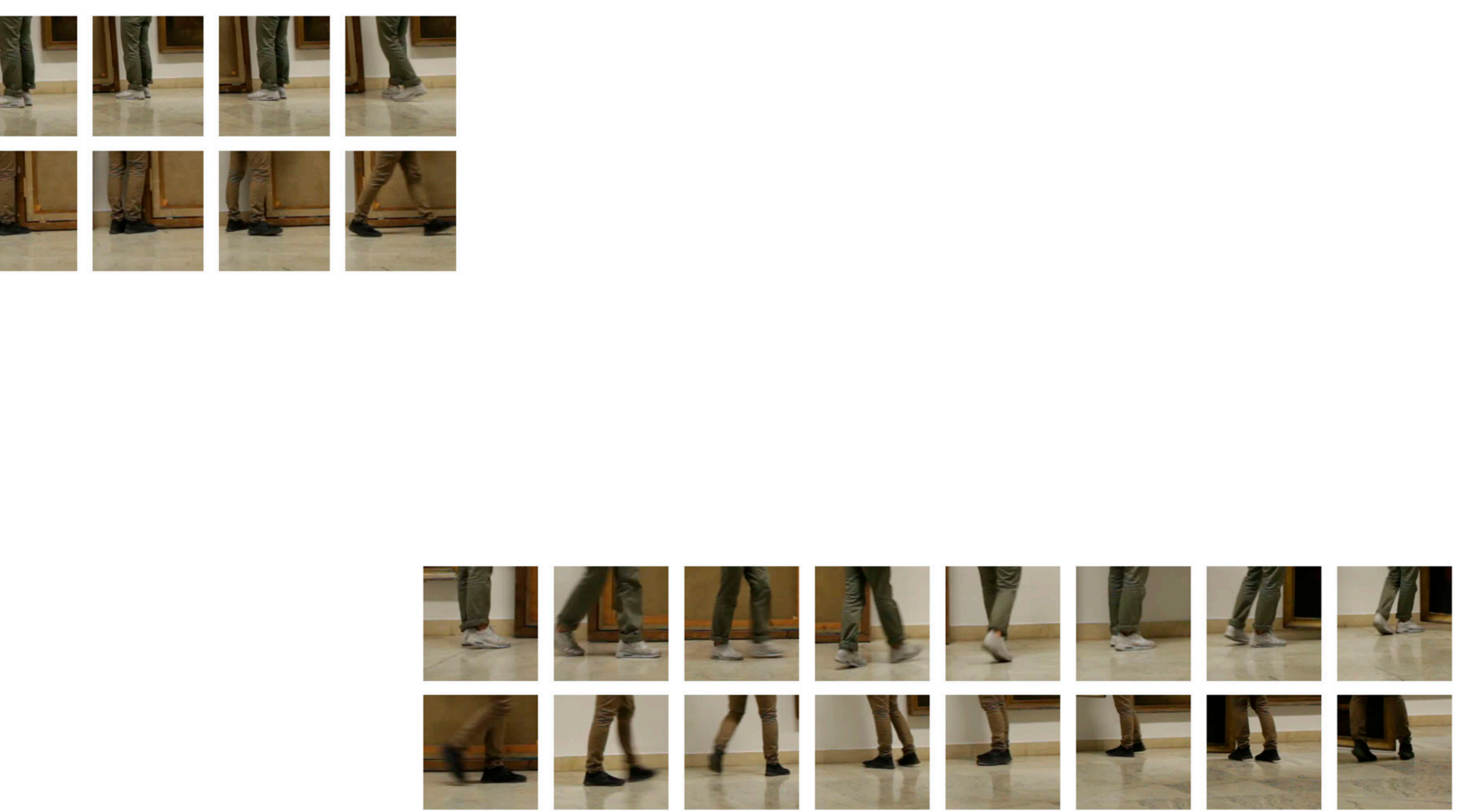

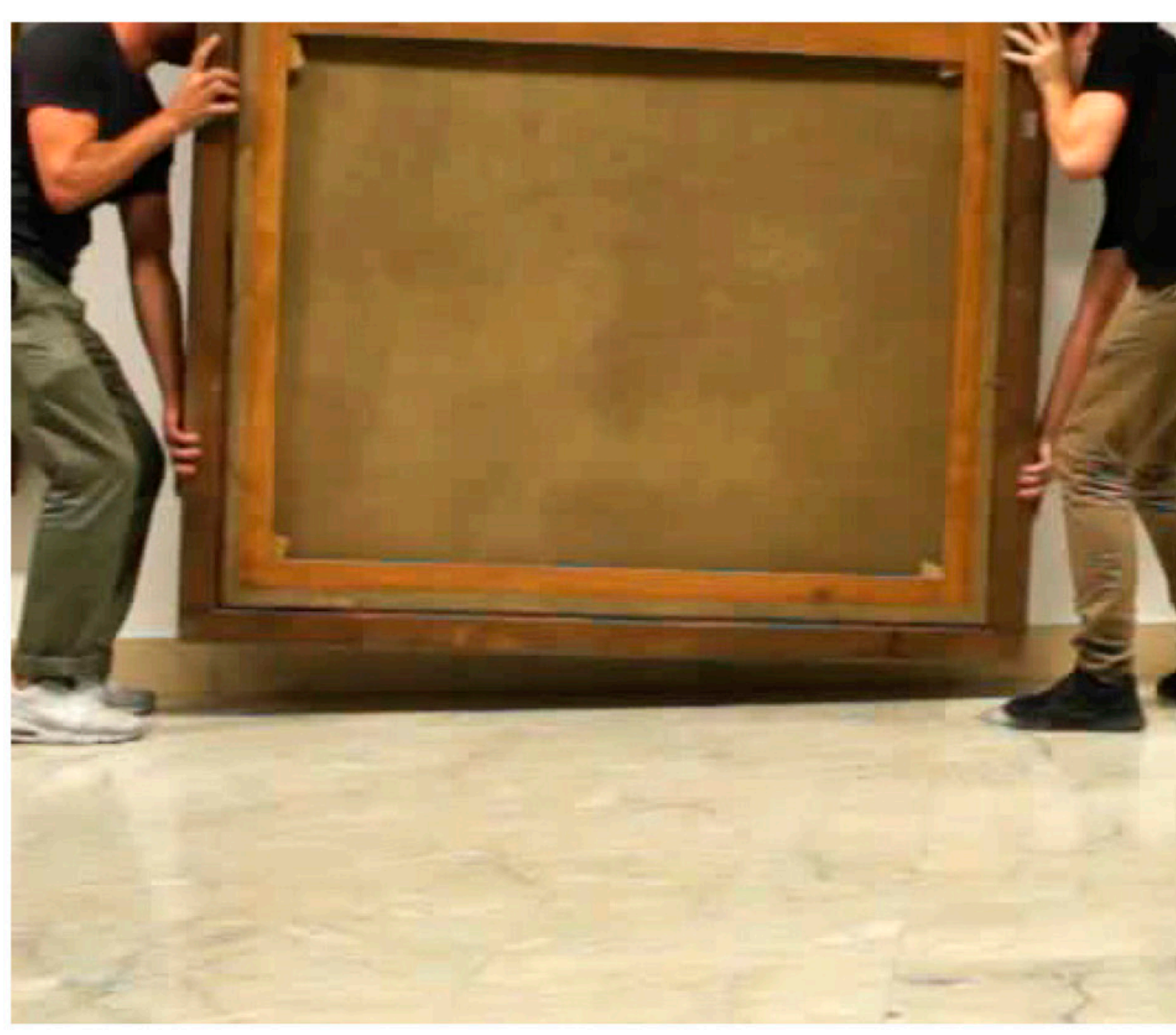

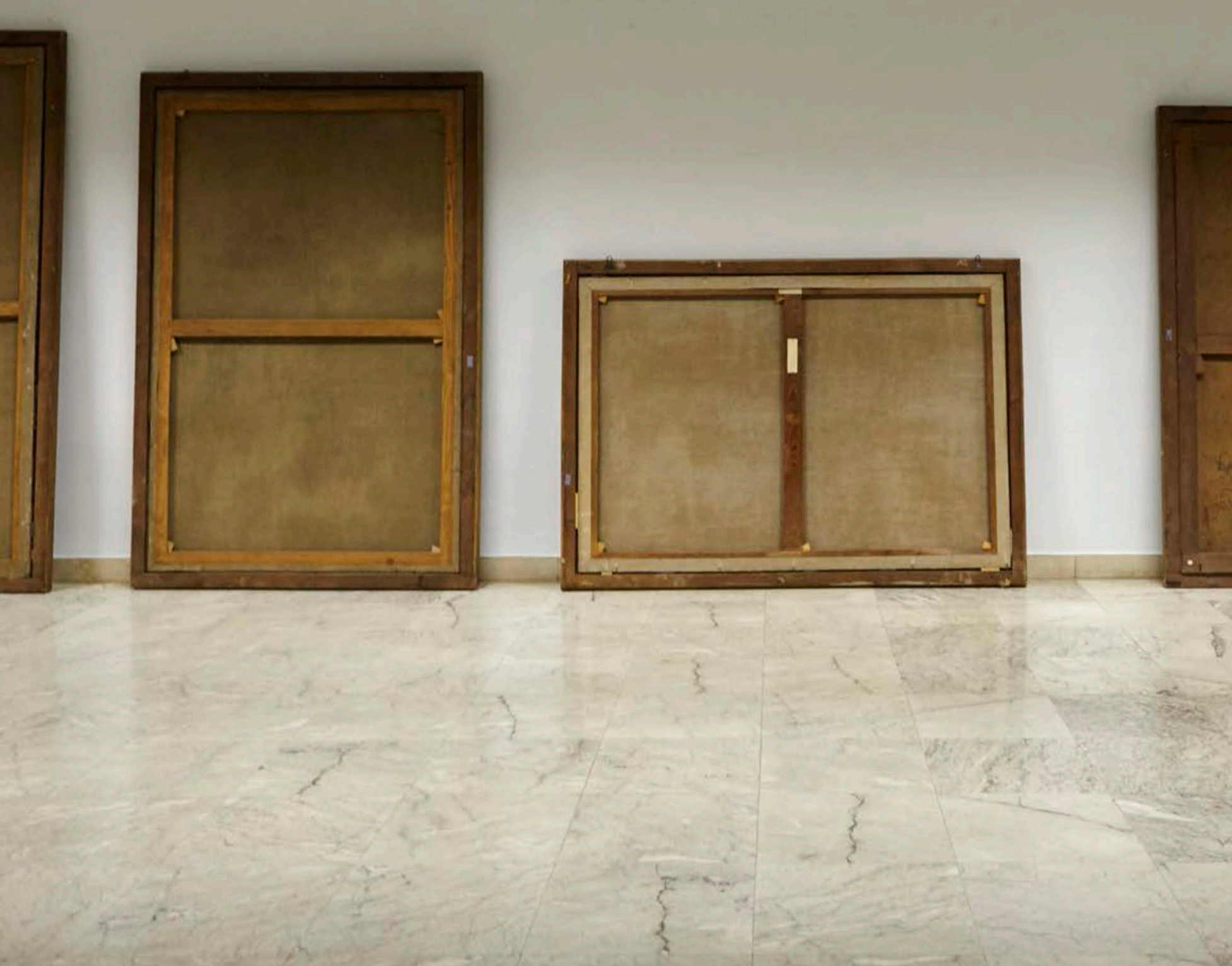